\title{
Article \\ Biocompatibility and Biological Performance Evaluation of Additive-Manufactured Bioabsorbable Iron-Based Porous Suture Anchor in a Rabbit Model
}

\author{
Chien-Cheng Tai ${ }^{1,+}{ }^{+}$Hon-Lok Lo ${ }^{2,+}$, Chen-Kun Liaw ${ }^{3,4,5}$, Yu-Min Huang ${ }^{3,4} \mathbb{D}^{\mathbb{D}}$, Yen-Hua Huang ${ }^{1,6,7}$, \\ Kuo-Yi Yang ${ }^{8}$, Chih-Chieh Huang ${ }^{8}$, Shin-I Huang ${ }^{8}$, Hsin-Hsin Shen ${ }^{8}$, Tzu-Hung Lin ${ }^{9}$, Chun-Kuan Lu ${ }^{10} \mathbb{D}^{\text {, }}$ \\ Wen-Chih Liu ${ }^{2,11,12}$ (D) Jui-Sheng Sun ${ }^{13,14}$, Pei-I Tsai ${ }^{8}$ (D) and Chih-Yu Chen ${ }^{3,4,5, * \mathbb{D}}$
}

Citation: Tai, C.-C.; Lo, H.-L.; Liaw, C.-K.; Huang, Y.-M.; Huang, Y.-H.; Yang, K.-Y.; Huang, C.-C.; Huang, S.-I; Shen, H.-H.; Lin, T.-H.; et al. Biocompatibility and Biological Performance Evaluation of Additive-Manufactured Bioabsorbable Iron-Based Porous Suture Anchor in a Rabbit Model. Int. J. Mol. Sci. 2021, 22, 7368. https://doi.org/10.3390/ijms22147368

Academic Editor: Barbara Zavan

Received: 17 May 2021

Accepted: 5 July 2021

Published: 8 July 2021

Publisher's Note: MDPI stays neutra with regard to jurisdictional claims in published maps and institutional affiliations.

Copyright: (c) 2021 by the authors. Licensee MDPI, Basel, Switzerland. This article is an open access article distributed under the terms and conditions of the Creative Commons Attribution (CC BY) license (https:// creativecommons.org/licenses/by/ $4.0 /)$
1 Internal Ph.D. Program for Cell Therapy and Regeneration Medicine, College of Medicine, Taipei Medical University, Taipei 11031, Taiwan; d151107007@tmu.edu.tw (C.-C.T.); rita1204@tmu.edu.tw (Y.-H.H.)

2 Department of Orthopedic Surgery, Kaohsiung Medical University Hospital, Kaohsiung Medical University, Kaohsiung 80756, Taiwan; honlok1021@hotmail.com (H.-L.L.); andysirliu@gmail.com (W.-C.L.)

3 Department of Orthopedics, School of Medicine, College of Medicine, Taipei Medical University, Taipei 11031, Taiwan; 17255@s.tmu.edu.tw (C.-K.L.); yellowcorn0326@yahoo.com.hk (Y.-M.H.)

4 Department of Orthopedics, Shuang Ho Hospital, Taipei Medical University, No. 291, Zhongzheng Rd., Zhong He Dist., New Taipei City 23561, Taiwan

5 Research Center of Biomedical Device, Graduate Institute of Biomedical Optomechatronics, College of Biomedical Engineering, Taipei Medical University, Taipei 11301, Taiwan

6 Department of Biochemistry and Molecular Cell Biology, School of Medicine, College of Medicine, Taipei Medical University, Taipei 11031, Taiwan

7 TMU Research Center of Cell Therapy and Regeneration Medicine, Taipei Medical University, Taipei 11031, Taiwan

8 Biomedical Technology and Device Research Laboratories, Industrial Technology Research Institute, Chutung, Hsinchu 310401, Taiwan; yangkuoyi@itri.org.tw (K.-Y.Y.); Sigher@itri.org.tw (C.-C.H.); sophiashini@itri.org.tw (S.-IH.); shenhsin@itri.org.tw (H.-H.S.); peiyi@itri.org.tw (P.-IT.)

9 Material and Chemical Research Laboratories, Industrial Technology Research Institute, Hsinchu 31040, Taiwan; DustyLin@itri.org.tw

10 Department of Orthopaedics, Park One International Hospital, Kaohsiung 813322, Taiwan; u9001054@yahoo.com.tw

11 Ph.D. Program in Biomedical Engineering, College of Medicine, Kaohsiung Medical University, Kaohsiung 807378, Taiwan

12 Regeneration Medicine and Cell Therapy Research Center, Kaohsiung Medical University, Kaohsiung 807378, Taiwan

13 Department of Orthopedics, China Medical University, Taichung 40202, Taiwan; drjssun@cmu.edu.tw

14 School of Medicine, College of Medicine, China Medical University, Taichung 40202, Taiwan

* Correspondence: aleckc2424@gmail.com; Tel.: +886-970-747767

$+\quad$ These authors contributed equally.

Abstract: This study evaluated the biocompatibility and biological performance of novel additivemanufactured bioabsorbable iron-based porous suture anchors (iron_SAs). Two types of bioabsorbable iron_SAs, with double- and triple-helical structures (iron_SA_2_helix and iron_SA_3_helix, respectively), were compared with the synthetic polymer-based bioabsorbable suture anchor (polymer_SAs). An in vitro mechanical test, MTT assay, and scanning electron microscope (SEM) analysis were performed. An in vivo animal study was also performed. The three types of suture anchors were randomly implanted in the outer cortex of the lateral femoral condyle. The ultimate in vitro pullout strength of the iron_SA_3_helix group was significantly higher than the iron_SA_2_helix and polymer_SA groups. The MTT assay findings demonstrated no significant cytotoxicity, and the SEM analysis showed cells attachment on implant surface. The ultimate failure load of the iron_SA_3_helix group was significantly higher than that of the polymer_SA group. The micro-CT analysis indicated the iron_SA_3_helix group showed a higher bone volume fraction (BV/TV) after surgery. Moreover, both iron SAs underwent degradation with time. Iron_SAs with triple-helical threads and a porous structure demonstrated better mechanical strength and high biocompatibility after short-term implantation. The combined advantages of the mechanical superiority of the iron 
metal and the possibility of absorption after implantation make the iron_SA a suitable candidate for further development.

Keywords: additive manufacturing (3D printing); bioabsorbable; iron-based; suture anchor

\section{Introduction}

Inert metals such as stainless steel, titanium alloys, and cobalt alloys have been widely used as orthopedic and cardiovascular implants because they demonstrate excellent corrosion resistance and possess adequate mechanical properties relative to local biological tissues [1-3]. Conventionally, these inert metallic implants are designed to permanently remain in the body until interventional removal [3,4]. However, the use of permanent inert materials for providing temporary support can cause several complications, such as stress shielding over time, leading to the weakening of the implanted tissue, development of foreign body sensations, distortion of diagnostic images, and requirement of secondary surgery to remove the implants $[1,4,5]$. Therefore, the use of self-degradable metallic implants in the body environment and the gradual transfer of the load onto the healing tissue until tissue recovery can be effective strategies for overcoming the drawbacks of inert metallic implants.

The majority of currently available bioabsorbable implants used clinically are made from biodegradable synthetic polymer compounds and have been approved by the Food and Drug Administration (FDA) [4,6,7]. However, these implants, prepared using biodegradable synthetic polymers, are usually not adequately stiff to be used in major load-bearing applications [8,9]. By contrast, recent advances in the development of biodegradable metallic materials have demonstrated the potential to revolutionize metallic implant designs and treatment strategies $[4,5,7,10-12]$. Implants prepared using biodegradable metals are significantly stronger than those developed using polymers; moreover, degraded metal particles are fully dissolvable in body fluids [5].

Iron-based biodegradable materials are considered to be a suitable candidate for use as metallic implants [13-16]. These materials have been demonstrated to have satisfactory cytocompatibility, and their mechanical properties can match those of the natural bone $[13,14,17,18]$. However, the slow degradation of iron-based biodegradable materials in the physiological environment is a major weakness, and this drawback should be overcome to enable their use in clinical applications $[5,13,14,19]$.

Increasing surface area and incorporation of porous structures into an iron-based biodegradable material can accelerate its degradation rate [5,20-23]. Our control group suture anchors were famous for its open architecture in appearance that had the higher surface area $[24,25]$. In this study, we innovated bioabsorbable iron-based porous suture anchors (hereafter referred to as iron SAs) by using control group suture anchor as reference template. On the other hand, in order to compare biomechanical performances among different appearances, we constructed our suture anchors with two different appearances (a double- and triple-helical structure, respectively) and incorporated porous structures in the threads by using additive manufacturing (AM) technology. We evaluated the biocompatibility (both in vivo and in vitro), biomechanical performance, micro-computed tomography (micro-CT) results, and histopathological analysis findings of iron SAs and compared them with those of synthetic polymer-based suture anchors (hereafter referred to as polymer SAs) by using a rabbit animal model. We hypothesized that iron SAs produced using AM technology are biocompatible and can outperform currently used polymer SAs.

\section{Results}

\subsection{In Vitro Mechanical Analyses of Bioabsorbable Iron SA}

The specifications and geometrical appearances of the two types of suture anchors are shown in Figure 1A,B. 

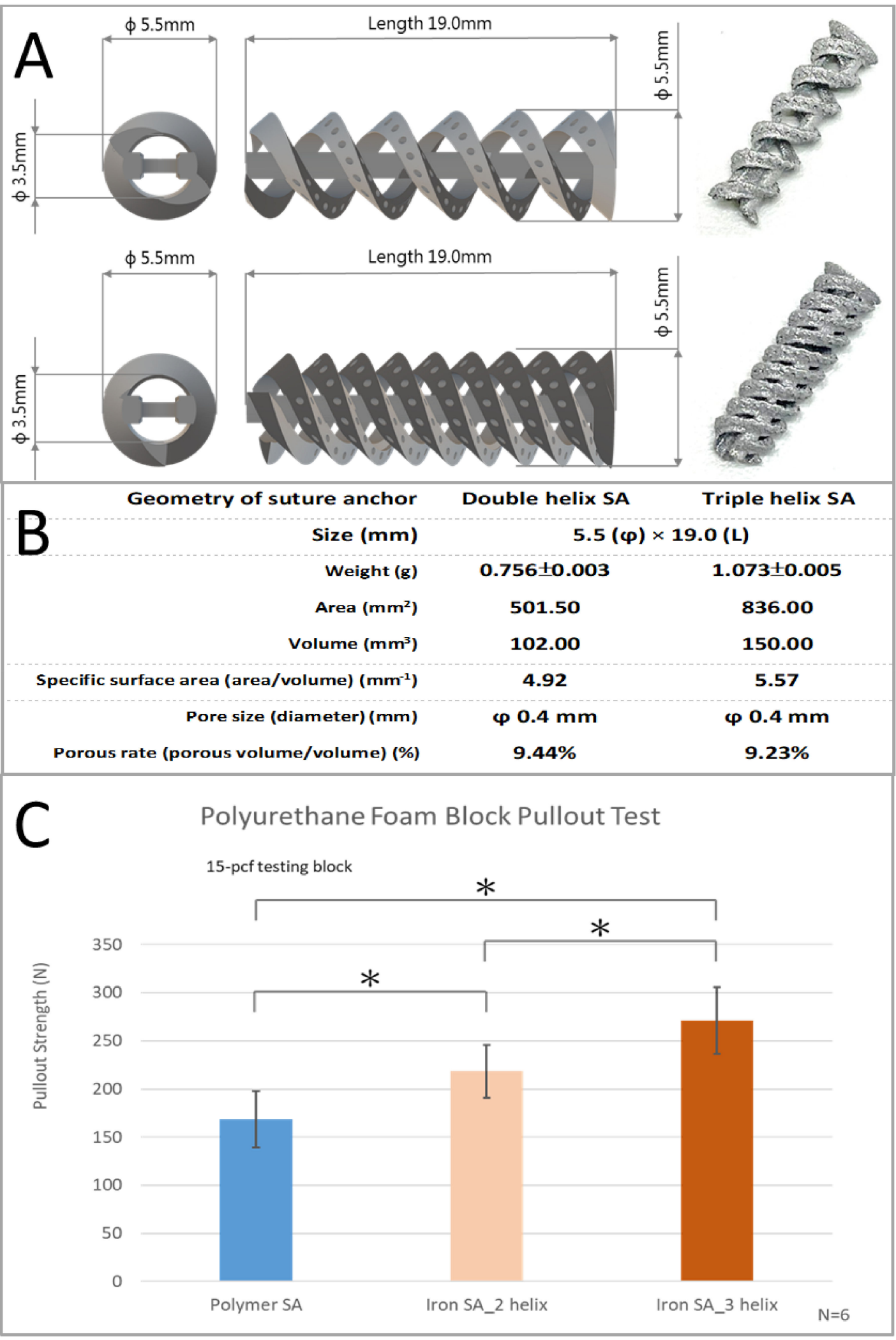

Figure 1. Illustration of iron-based bioabsorbable porous double- and triple-helical suture anchors (A). Geometrical specifications of iron-based bioabsorbable porous double- and triple-helical suture anchors (B). In vitro mechanical ultimate pullout strength test of three types of suture anchors $(\mathbf{C})$. The error bar represents the standard deviation, and * denotes statistical significance between the two groups. 
The ultimate in vitro pullout strength was significantly higher for the iron SA_3 helix $(270.94 \pm 34.76 \mathrm{~N})$ than for the iron SA_2 helix $(218.43 \pm 27.53 \mathrm{~N}, p=0.0158)$ and the polymer SA (168.54 $\pm 29.45 \mathrm{~N}, p=0.0003)$. In addition, the ultimate in vitro pullout strength was significantly higher for the iron SA_2 helix than for the polymer SA $(p=0.0126)$. These results are shown in Figure 1B and Table 1.

Table 1. In vitro ultimate pullout strength of suture anchors.

\begin{tabular}{cccc}
\hline Group & Pullout Strength (N) & $p$ Value vs. Polymer SA & $p$ Value vs. Polymer SA \\
\hline Polymer SA & $168.54 \pm 29.45$ & & \\
Iron SA_2 Helix & $218.43 \pm 27.53$ & 0.0126 & \\
Iron SA_3 Helix & $270.94 \pm 34.76$ & 0.0003 & 0.0158 \\
\hline
\end{tabular}

\subsection{In Vitro Biocompatibility Analyses of Bioabsorbable Iron $S A$}

As shown in Figure 2A and Table 2, the findings of the MTT assay demonstrated no significant cytotoxicity in the two groups treated with the iron SA extracts. In addition, the results of the SEM analysis exhibited the attachment of cells onto the implant surface accompanied with lamellipodial and filopodial extrusions from the cells (Figure 2B). These findings suggest that cells could attach onto the implant surface and explore the environment without experiencing significant cytotoxicity.

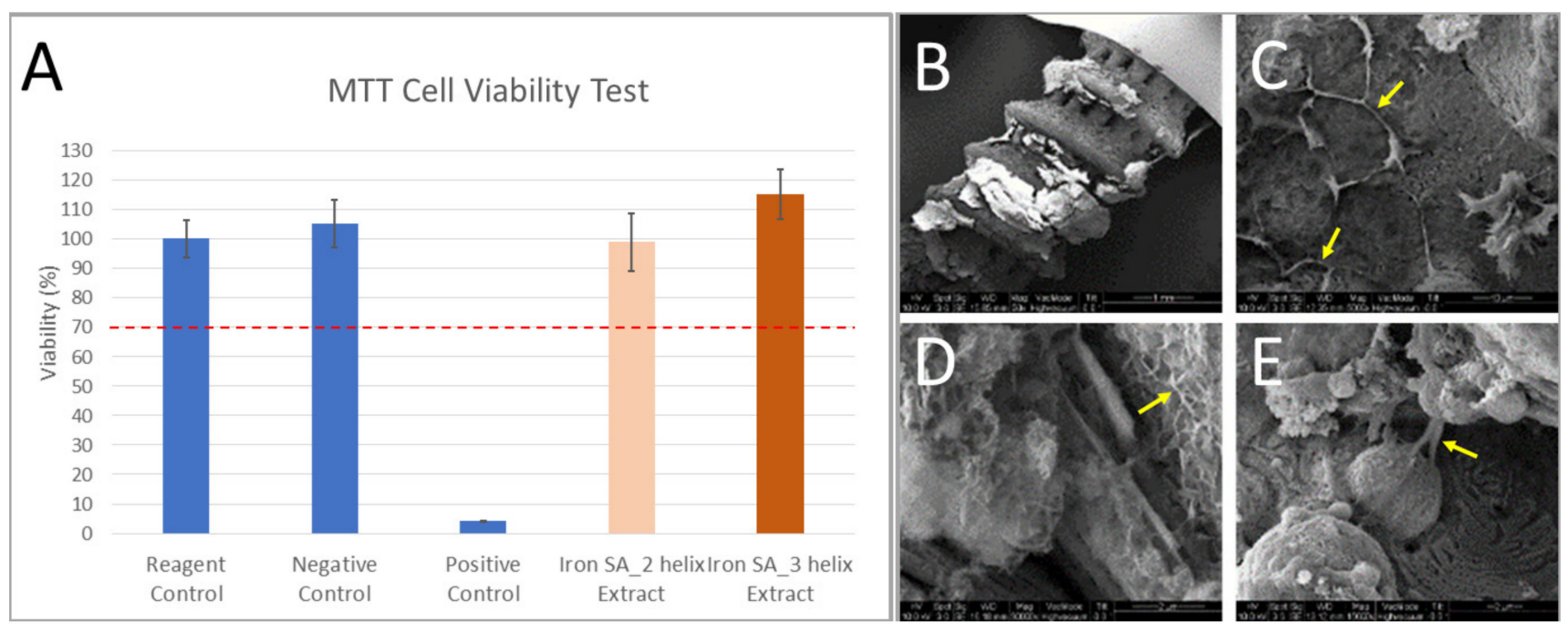

Figure 2. The 3-(4,5-dimethylthiazol-2-yl)-2,5-diphenyl tetrazolium bromide (MTT) assays were performed for the extracts of iron-based bioabsorbable porous suture anchors of different groups (A) which showed $>70 \%$ cell viability. Scanning electron microscope (SEM) analysis of iron-based bioabsorbable porous testing suture anchors (prototype, not final version) (B) demonstrated cell attachment on the implant surface. Yellow arrows indicated the lamellipodial and filopodial extrusions from the cells (C-E). The error bar represented the standard deviation.

Table 2. MTT cell viability assay.

\begin{tabular}{cc}
\hline & Viability \pm SD (\%) \\
\hline Reagent Control & $100 \pm 6.46$ \\
Negative Control & $105.1 \pm 7.95$ \\
Positive Control & $4.22 \pm 0.12$ \\
Iron SA_2 Helix Extract & $98.83 \pm 9.61$ \\
Iron SA_3 Helix Extract & $115.08 \pm 8.45$ \\
\hline
\end{tabular}




\subsection{In Vivo Biomechanical Analysis}

The findings of biomechanical analysis revealed that the ultimate failure load of the iron SA_3 helix group at 4 weeks $(162.36 \pm 23.02 \mathrm{~N})$ was significantly stronger than that of the iron SA_2 helix group $(216.23 \pm 20.07 \mathrm{~N}, p=0.0004)$ and the polymer SA group $(257.85 \pm 38.66 \mathrm{~N}, p=0.0413)$. At 12 weeks, the ultimate failure load of the iron SA_2 helix and iron SA_3 helix groups ( $318.59 \pm 36.58 \mathrm{~N}$ and $361.97 \pm 69.45 \mathrm{~N}$, respectively) were significantly higher than that of the polymer SA group $(198.80 \pm 14.28 \mathrm{~N} ; p=0.0001$ and $p=0.0002$, respectively). However, at 12 weeks, the ultimate pullout strength did not significantly differ between the iron SA_2 helix and iron SA_3 helix groups $(p=0.2056)$. The data are shown in Figure 3 and Table 3.

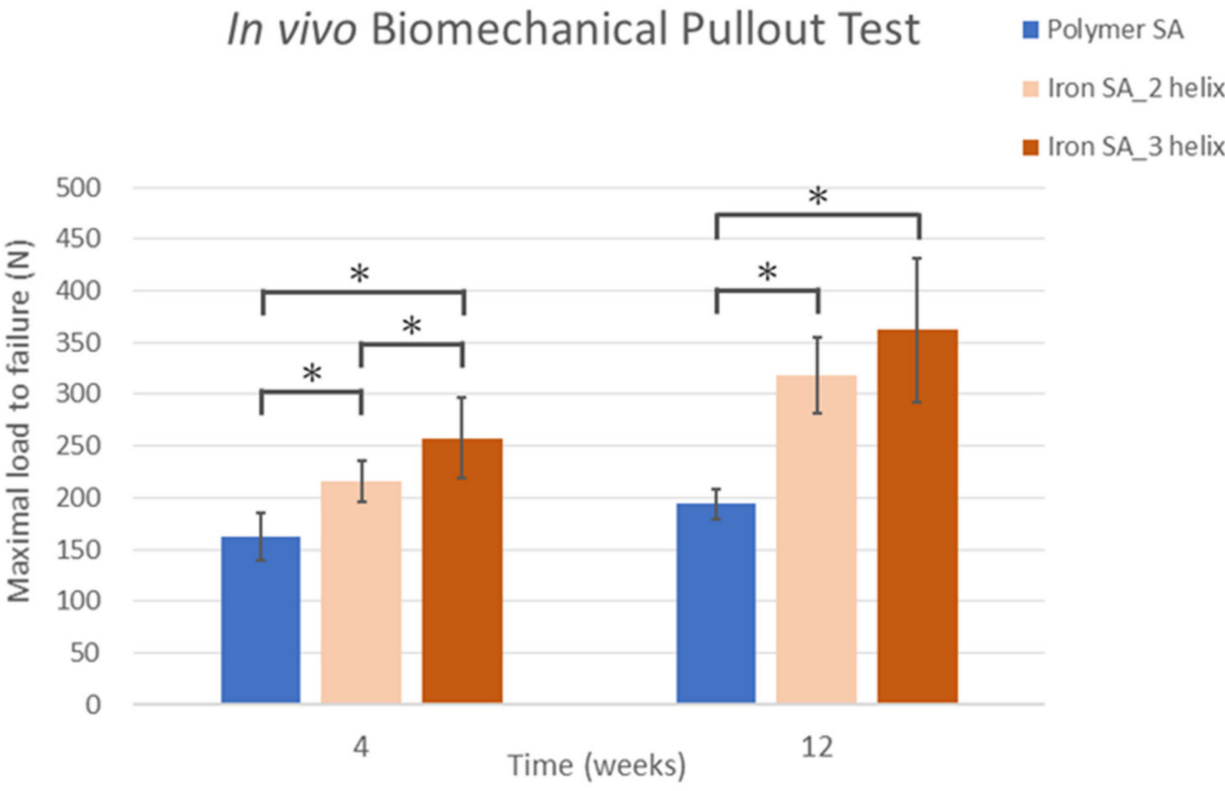

Figure 3. In vivo biomechanical ultimate pullout strength assessment for different suture anchors. The ultimate failure load of the iron SA_3 helix group at 4 weeks was significantly higher than those of the iron SA_2 helix and Polymer SA groups. At 12 weeks, the ultimate failure load of the iron SA_2 helix and iron SA_3 helix groups were significantly higher than that of the polymer SA group The error bar represents the standard deviation, and * denotes statistical significance between the two groups.

Table 3. In vivo biomechanical ultimate pullout test.

\begin{tabular}{|c|c|c|c|c|}
\hline \multicolumn{5}{|c|}{ Inter-Group Statistical Analysis } \\
\hline Weeks & Group & Pullout Strength (N) & $p$ Value vs. Polymer SA & $p$ Value vs. Iron SA_2 Helix \\
\hline \multirow{4}{*}{4} & Polymer SA & $162.36 \pm 23.02$ & & \\
\hline & Iron SA_2 Helix & $216.23 \pm 20.07$ & 0.015 & \\
\hline & Iron SA_3 Helix & $257.85 \pm 38.66$ & 0.004 & 0.0413 \\
\hline & Polymer SA & $193.80 \pm 14.28$ & & \\
\hline \multirow[t]{2}{*}{12} & Iron SA_2 Helix & $318.59 \pm 36.58$ & 0.0001 & \\
\hline & Iron SA_3 Helix & $361.97 \pm 69.45$ & 0.0002 & 0.2056 \\
\hline \multicolumn{5}{|c|}{ Intra-group statistical analysis } \\
\hline \multicolumn{2}{|c|}{ Group } & \multicolumn{3}{|c|}{$p$ value between 4 vs. 12 weeks } \\
\hline \multicolumn{2}{|c|}{ Polymer SA } & \multicolumn{3}{|c|}{0.0175} \\
\hline \multicolumn{2}{|c|}{ Iron SA_2 helix } & \multicolumn{3}{|c|}{0.0001} \\
\hline \multicolumn{2}{|c|}{ Iron SA_3 helix } & \multicolumn{3}{|c|}{0.0094} \\
\hline
\end{tabular}


The ultimate failure load significantly increased from 4 to 12 weeks in all the groups. The results are shown in Table 3.

\subsection{Micro-CT Analysis}

Micro-CT was performed to evaluate bone formation between the implant and bone tissue (Figure 4A). Compared with the polymer SA group, the iron SA groups had higher $\mathrm{BV} / \mathrm{TV}$ at both 4 and 12 weeks postoperatively; however, this difference was not significant ( $p=0.8102$ and $p=0.2395$ at 4 weeks and $p=0.5319$ and $p=0.4097$ at 12 weeks, respectively). The results are shown in Figure $4 \mathrm{~B}$ and Table 4 . These results suggest that both the polymer SA and iron SA resulted in favorable bone growth. In addition, the iron SA groups had a higher BS/TV percentage 12 weeks postoperatively (Figure $4 \mathrm{C}$ and Table 4 ); however, this difference was not statistically significant $(p=0.1656$ and $p=0.1630$, respectively). A higher BS/TV indicated increased bone growth closer $(<1000 \mu \mathrm{m})$ to the implant surface region. Our results demonstrated that compared with the polymer SA, the iron SA led to increased bone growth, especially at the region near the implant surface.

Table 4. Micro-CT analysis.

\begin{tabular}{|c|c|c|c|c|}
\hline \multicolumn{5}{|c|}{ BV/TV Inter-Group Statistical Analysis } \\
\hline Weeks & Group & BV/TV (\%) & $\begin{array}{l}p \text { Value vs. } \\
\text { Polymer SA }\end{array}$ & $\begin{array}{l}p \text { Value vs. Iron } \\
\text { SA_2 Helix }\end{array}$ \\
\hline \multirow{3}{*}{4} & Polymer SA & $29.04 \pm 7.57$ & & \\
\hline & Iron SA_2 Helix & $30.19 \pm 8.55$ & 0.8102 & \\
\hline & Iron SA_3 Helix & $34.42 \pm 7.33$ & 0.2395 & 0.3792 \\
\hline \multirow{3}{*}{12} & Polymer SA & $27.01 \pm 11.86$ & & \\
\hline & Iron SA_2 Helix & $31.02 \pm 9.46$ & 0.5319 & \\
\hline & Iron SA_3 Helix & $32.89 \pm 11.81$ & 0.4097 & 0.7683 \\
\hline \multicolumn{5}{|c|}{ BV/TV Intra-Group Statistical Analysis } \\
\hline \multicolumn{2}{|c|}{ Group } & \multicolumn{3}{|c|}{$p$ Value between 4 vs. 12 Weeks } \\
\hline \multirow{3}{*}{\multicolumn{2}{|c|}{$\begin{array}{c}\text { Polymer SA } \\
\text { Iron SA_2 Helix } \\
\text { Iron SA_3 Helix }\end{array}$}} & \multicolumn{3}{|c|}{0.7311} \\
\hline & & \multicolumn{3}{|c|}{0.8765} \\
\hline & & \multicolumn{3}{|c|}{0.7929} \\
\hline \multicolumn{5}{|c|}{ BS/TV Inter-Group Statistical Analysis } \\
\hline Weeks & Group & BS/TV (\%) & $\begin{array}{l}p \text { Value vs. } \\
\text { Polymer SA }\end{array}$ & $\begin{array}{l}p \text { Value vs. Iron } \\
\text { SA_2 Helix }\end{array}$ \\
\hline \multirow{4}{*}{4} & Polymer SA & $6.52 \pm 1.80$ & & \\
\hline & Iron SA_2 Helix & $5.60 \pm 1.04$ & 0.3038 & \\
\hline & Iron SA_3 Helix & $6.84 \pm 1.82$ & 0.7657 & 0.1780 \\
\hline & Polymer SA & $4.25 \pm 2.64$ & & \\
\hline \multirow[t]{2}{*}{12} & Iron SA_2 Helix & $6.85 \pm 3.34$ & 0.1656 & \\
\hline & Iron SA_3 Helix & $7.13 \pm 3.87$ & 0.1630 & 0.8959 \\
\hline \multicolumn{5}{|c|}{ BS/TV Intra-Group Statistical Analysis } \\
\hline \multicolumn{2}{|c|}{ Group } & \multicolumn{3}{|c|}{$p$ value between 4 vs. 12 Weeks } \\
\hline \multicolumn{2}{|c|}{ Polymer SA } & \multicolumn{3}{|c|}{0.1124} \\
\hline \multicolumn{2}{|c|}{ Iron SA_2 Helix } & \multicolumn{3}{|c|}{0.4020} \\
\hline \multicolumn{2}{|c|}{ Iron SA_3 Helix } & \multicolumn{3}{|c|}{0.8714} \\
\hline
\end{tabular}

The results of iron SA degradation analysis showed that the ST decreased and the SSV/OV increased sequentially from the preoperative period until 12 weeks postoperatively (Figure 5A,B and Table 5, respectively). These findings are also illustrated in the reconstructed micro-CT images shown in Figure 5C. These results indicate that the iron SA gradually degraded into smaller fragments, had decreased structural thickness, and had an increased total surface area after implantation. 

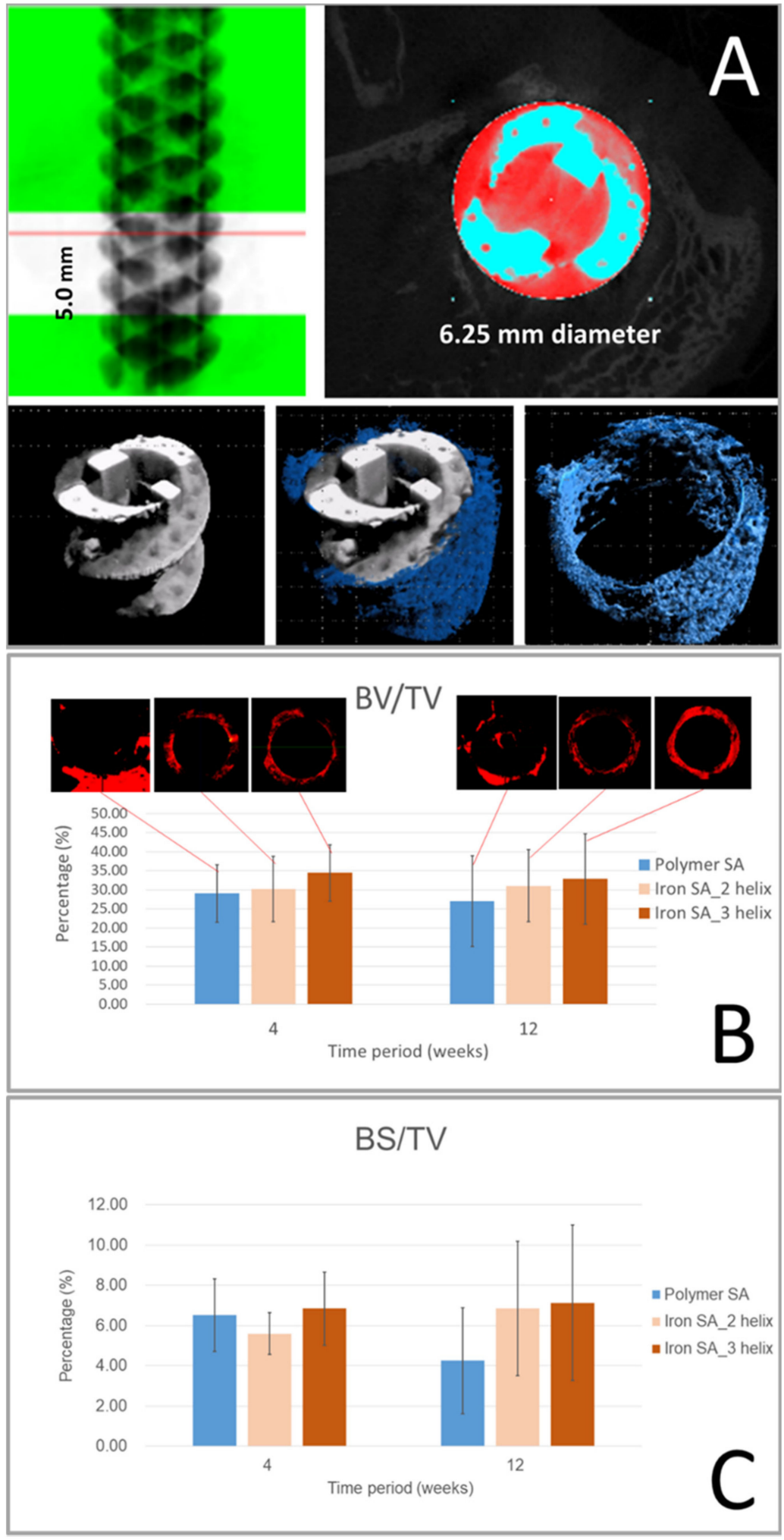

Figure 4. Micro-computed tomography (Micro-CT) analysis. The region of interest (ROI; diameter, $6.25 \mathrm{~mm}$; thickness, $5 \mathrm{~mm}$ ) of the bone-implant block was segmented before bone analysis, and bone growth was examined 0-1000 $\mu \mathrm{m}$ around the implant (A). Quantitative evaluation of bone volume between bone and suture anchors. Tissue volume (TV, $\mathrm{mm} 3)$, bone volume (BV, $\mathrm{mm} 3)$, and bone surface (BS, mm2) were examined 0-1000 $\mu \mathrm{m}$ above the implant surface. Bone volume fraction $(\mathrm{BV} / \mathrm{TV})(\mathrm{B})$ and bone surface density (BS/TV) (C) represent the bone volume rate and bone tissue surface rate, respectively. The error bar represents the standard deviation. 

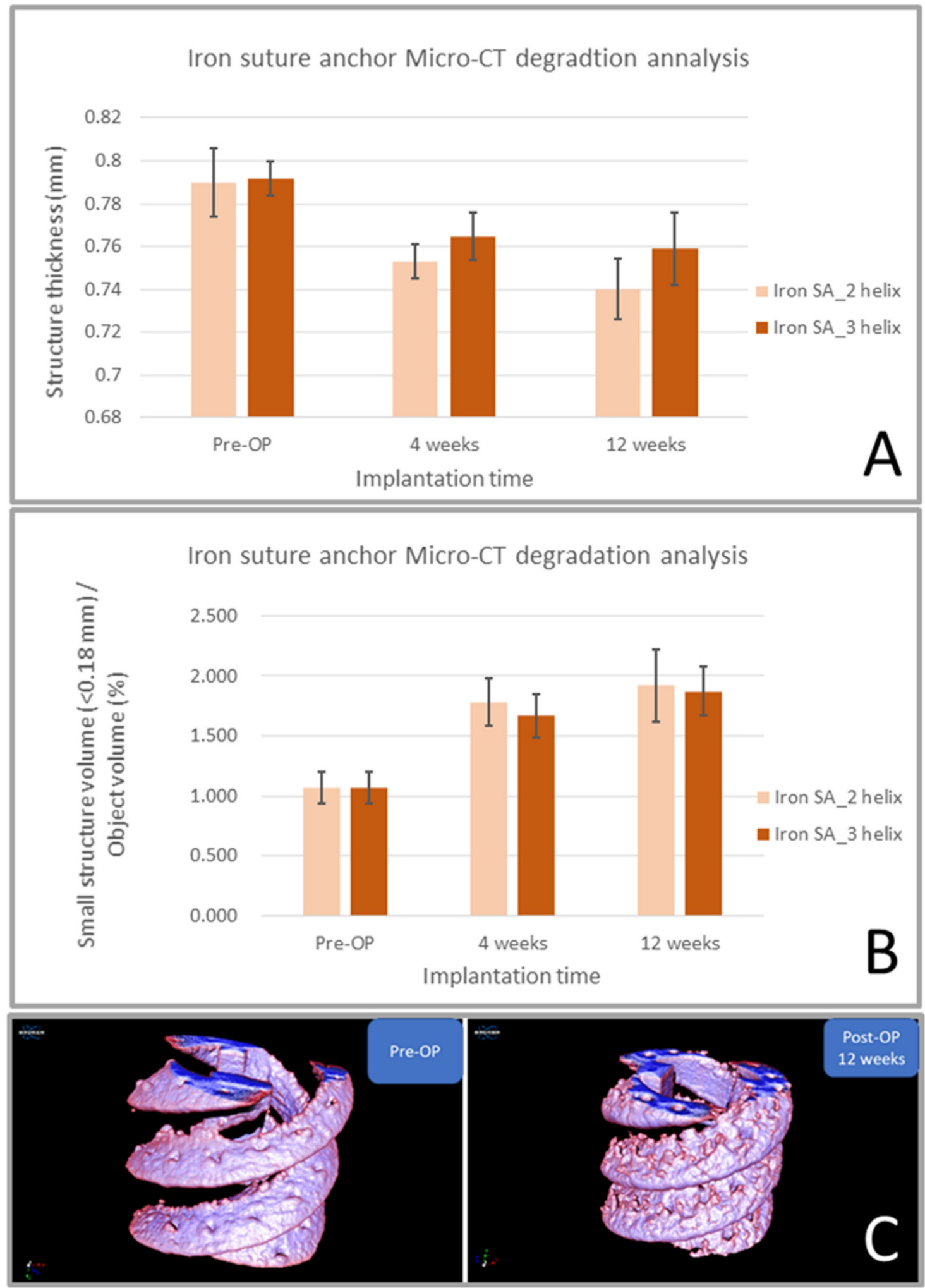

Figure 5. Micro-computed tomography (CT) degradation analysis of the iron suture groups. ST decreased (A) and SSV/OV percentage increased (B) sequentially from the preoperative period until 12 weeks postoperatively. Reconstructed micro-CT images observed preoperatively and at 12 weeks postoperatively (C). ST: structure thickness (mm), SSV: small implant fragments < $0.18 \mathrm{~mm}$ in diameter (small-structure volume), OV: object volume, and SSV /OV (\%) denoted the small fragment percentage of the implant in the region of interest. The error bar represents the standard deviation. 
Table 5. Micro-CT degradation analysis of the iron suture anchor for structure thickness (ST) and small-structure volume $(<0.18 \mathrm{~mm})(\mathrm{SSV}) /$ object volume $(\mathrm{OV})$.

\begin{tabular}{|c|c|c|c|c|}
\hline \multicolumn{5}{|c|}{ ST Inter-Group Statistical Analysis } \\
\hline Weeks & Group & $\mathrm{ST}(\mathrm{mm})$ & $p$ Value vs. Pre-OP & $p$ Value vs. 4 Weeks \\
\hline \multirow{2}{*}{ Pre-OP } & Iron SA_2 helix & $0.790 \pm 0.016$ & & \\
\hline & Iron SA_3 helix & $0.792 \pm 0.008$ & & \\
\hline \multirow{2}{*}{4} & Iron SA_2 helix & $0.753 \pm 0.008$ & 0.0005 & \\
\hline & Iron SA 3 helix & $0.765 \pm 0.011$ & 0.0007 & \\
\hline \multirow[b]{2}{*}{12} & Iron SA_2 helix & $0.740 \pm 0.014$ & 0.0002 & 0.0765 \\
\hline & Iron SA_3 helix & $0.759 \pm 0.017$ & 0.0016 & 0.4846 \\
\hline \multicolumn{5}{|c|}{ ST Intra-Group Statistical Analysis } \\
\hline \multicolumn{2}{|c|}{ Time period } & \multicolumn{3}{|c|}{$p$ value between 2 vs. 3 helix } \\
\hline \multicolumn{2}{|c|}{ Pre-OP } & \multicolumn{3}{|c|}{0.7898} \\
\hline \multicolumn{2}{|c|}{4 weeks } & \multicolumn{3}{|c|}{0.056} \\
\hline \multicolumn{2}{|c|}{12 weeks } & \multicolumn{3}{|c|}{0.0607} \\
\hline \multicolumn{5}{|c|}{ SSV/OV Inter-Group Statistical Analysis } \\
\hline Weeks & Group & SSV/OV (\%) & $p$ Value vs. Pre-OP & $p$ Value vs. 4 Weeks \\
\hline \multirow{2}{*}{ Pre-OP } & Iron SA_2 helix & $1.068 \pm 0.128$ & & \\
\hline & Iron SA_3 helix & $1.064 \pm 0.132$ & & \\
\hline \multirow{2}{*}{4} & Iron SA_2 helix & $1.780 \pm 0.194$ & 0.0001 & \\
\hline & Iron SA_3 helix & $1.666 \pm 0.179$ & 0.0001 & \\
\hline \multirow{2}{*}{12} & Iron SA_2 helix & $1.920 \pm 0.301$ & 0.0001 & 0.3608 \\
\hline & Iron SA_3 helix & $1.871 \pm 0.205$ & 0.0001 & 0.0948 \\
\hline \multicolumn{5}{|c|}{ SSV/OV Intra-Group Statistical Analysis } \\
\hline \multicolumn{2}{|c|}{ Time period } & \multicolumn{3}{|c|}{$p$ value between 2 vs. 3 Helix } \\
\hline \multirow{3}{*}{\multicolumn{2}{|c|}{$\begin{array}{c}\text { Pre-OP } \\
4 \text { weeks }\end{array}$}} & \multicolumn{3}{|c|}{0.9586} \\
\hline & & & 0.315 & \\
\hline 12 weeks & & \multicolumn{3}{|c|}{0.7485} \\
\hline
\end{tabular}

\subsection{Biochemical Analysis}

For the biochemical analysis, blood samples were collected from all the rabbits immediately preoperatively and 4,8 , and 12 weeks postoperatively. The concentrations of iron, ALT, Cr, and BUN were determined. The results are shown in Figure 6 and Table 6.

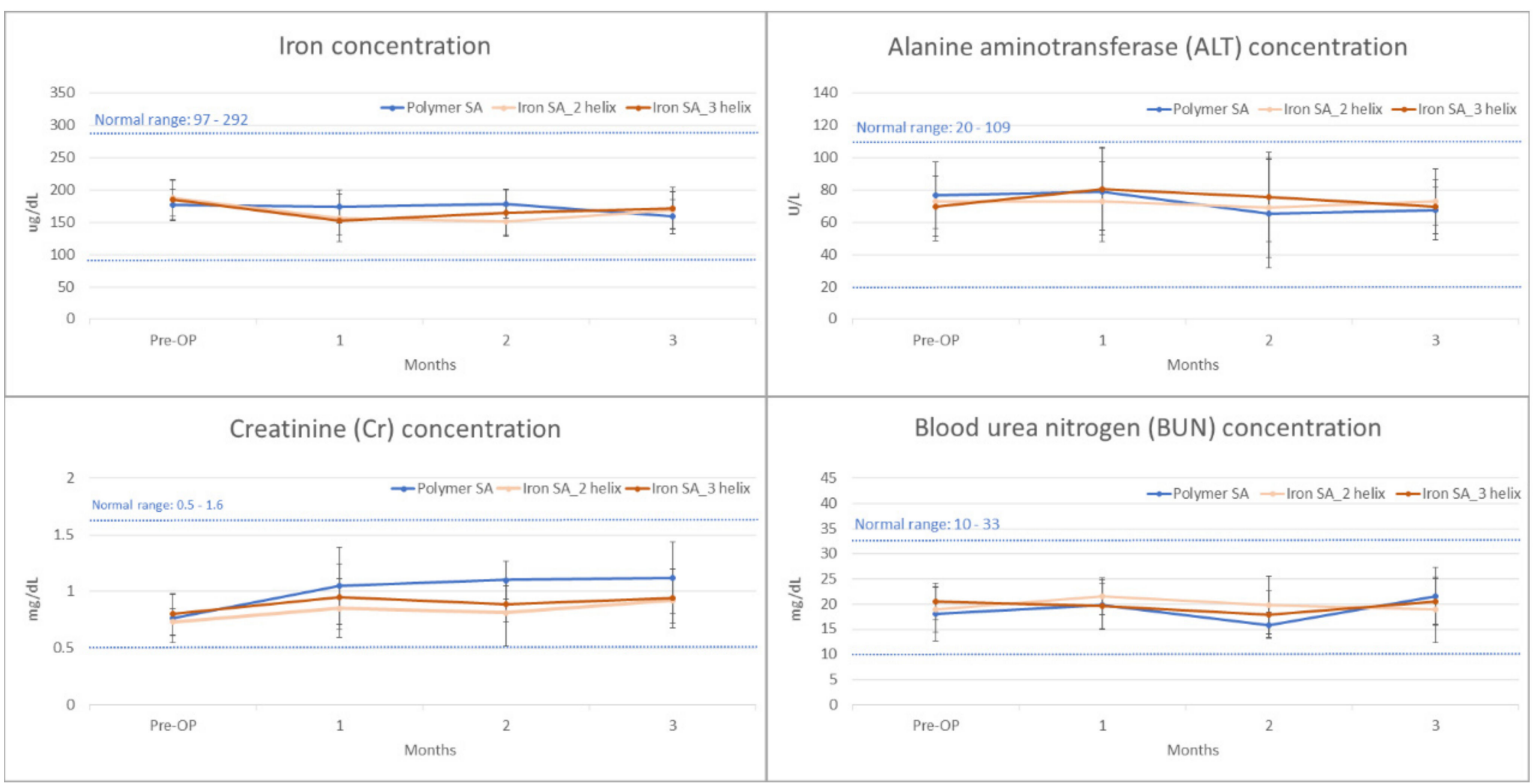

Figure 6. Blood concentrations of iron $(\mu \mathrm{g} / \mathrm{dL})$, alanine transaminase (ALT; U/L), creatinine (Cr; $\mathrm{mg} / \mathrm{dL}$ ), and blood urea nitrogen $(\mathrm{BUN} ; \mathrm{mg} / \mathrm{dL})$ preoperatively and 1, 2, and 3 months postoperatively. The error bar represented the standard deviation. 
Table 6. Blood biochemistry analysis.

\begin{tabular}{|c|c|c|c|c|}
\hline & \multicolumn{4}{|c|}{ Iron Concentration $(\mu \mathrm{g} / \mathrm{dL})$} \\
\hline & Pre-OP & 4 Weeks & 8 Weeks & 12 Weeks \\
\hline Polymer SA & $176.39 \pm 24.84$ & $173.51 \pm 25.49$ & $178.48 \pm 21.97$ & $158.43 \pm 26.28$ \\
\hline Iron SA_2 Helix & $186.85 \pm 28.54$ & $156.87 \pm 36.52$ & $150.87 \pm 23.68$ & $168.96 \pm 28.57$ \\
\hline \multirow[t]{3}{*}{ Iron SA_3 Helix } & $184.54 \pm 30.58$ & $152.47 \pm 22.25$ & $164.86 \pm 34.85$ & $170.65 \pm 32.58$ \\
\hline & \multicolumn{4}{|c|}{ Alanine Transaminase (ALT) Concentration (U/L) } \\
\hline & Pre-OP & 4 weeks & 8 weeks & 12 weeks \\
\hline Polymer SA & $76.58 \pm 20.58$ & $78.52 \pm 26.54$ & $65.44 \pm 33.52$ & $67.61 \pm 18.72$ \\
\hline Iron SA_2 Helix & $72.86 \pm 24.27$ & $72.54 \pm 24.20$ & $68.84 \pm 30.79$ & $72.86 \pm 20.11$ \\
\hline \multirow[t]{3}{*}{ Iron SA_3 Helix } & $69.68 \pm 18.57$ & $80.54 \pm 25.67$ & $75.28 \pm 27.65$ & $69.81 \pm 11.92$ \\
\hline & \multicolumn{4}{|c|}{ Creatinine $(\mathrm{Cr})$ Concentration $(\mathrm{mg} / \mathrm{dL})$} \\
\hline & Pre-OP & 4 weeks & 8 weeks & 12 weeks \\
\hline Polymer SA & $0.76 \pm 0.21$ & $1.05 \pm 0.34$ & $1.10 \pm 0.17$ & $1.12 \pm 0.32$ \\
\hline Iron SA_2 Helix & $0.73 \pm 0.12$ & $0.85 \pm 0.26$ & $0.81 \pm 0.29$ & $0.92 \pm 0.20$ \\
\hline \multirow[t]{3}{*}{ Iron SA_3 Helix } & $0.80 \pm 0.18$ & $0.95 \pm 0.29$ & $0.89 \pm 0.16$ & $0.94 \pm 0.26$ \\
\hline & \multicolumn{4}{|c|}{ Blood Urea Nitrogen (BUN) Concentration $(\mathrm{mg} / \mathrm{dL})$} \\
\hline & Pre-OP & 4 weeks & 8 weeks & 12 weeks \\
\hline Polymer SA & $17.99 \pm 5.31$ & $19.85 \pm 4.97$ & $15.87 \pm 2.59$ & $21.52 \pm 5.81$ \\
\hline Iron SA_2 Helix & $18.85 \pm 4.52$ & $21.54 \pm 3.58$ & $19.83 \pm 5.78$ & $18.85 \pm 6.58$ \\
\hline Iron SA_3 Helix & $20.54 \pm 3.67$ & $19.63 \pm 4.57$ & $17.88 \pm 4.73$ & $20.52 \pm 4.52$ \\
\hline
\end{tabular}

\subsection{Histological and Histopathological Analyses}

Bone formation was observed both in the polymer SA and iron SA groups (Figure 7). In all histological analyses, particularly at a high magnification field, new bone growth was observed in the region closely contacted to the suture anchors. The findings of the polymer SA are compatible with those of previous studies [26,27]. Our results revealed high biocompatibility of the iron SA; this finding is compatible with those of the MTT assay and SEM analysis (Figure 2A,B).

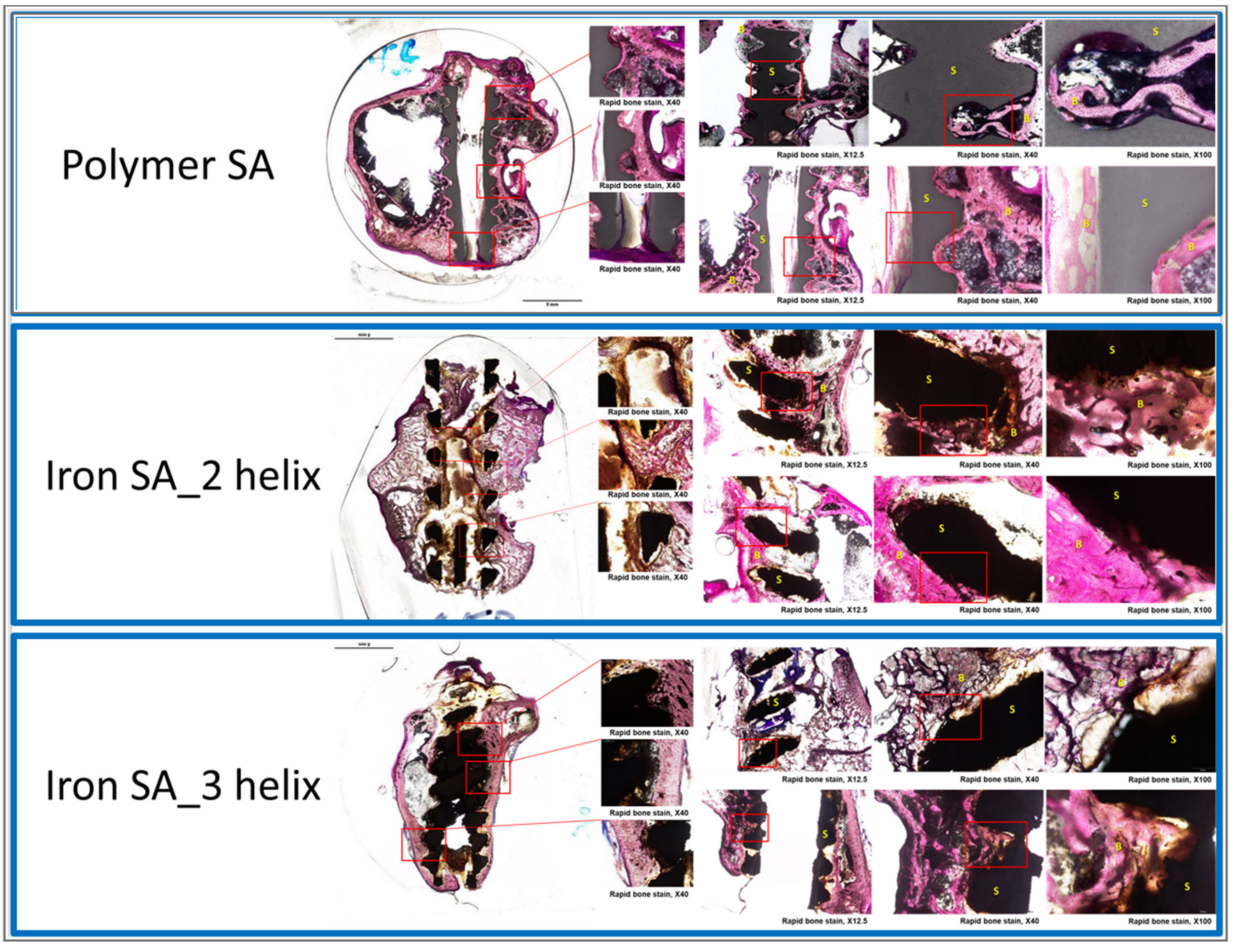

Figure 7. Histological examination of the bone-suture anchor interface. The specimens were stained with Sanderson's rapid bone stain and then counterstained with acid fuchsin. Scale from $12.5 \times, 40 \times$, and $100 \times$, respectively. B: bone, S: suture anchor. 
The histopathological findings of the liver, spleen, heart, and kidneys did not significantly differ between the iron SA group and the polymer SA group. Figure 8 shows the histopathological specimens of the visceral organs obtained from one of the animals in the iron SA_3 helix group. Figure 9 presents the findings of the Prussian blue staining of the liver and spleen, and Table 7 lists the semi-quantitative results.

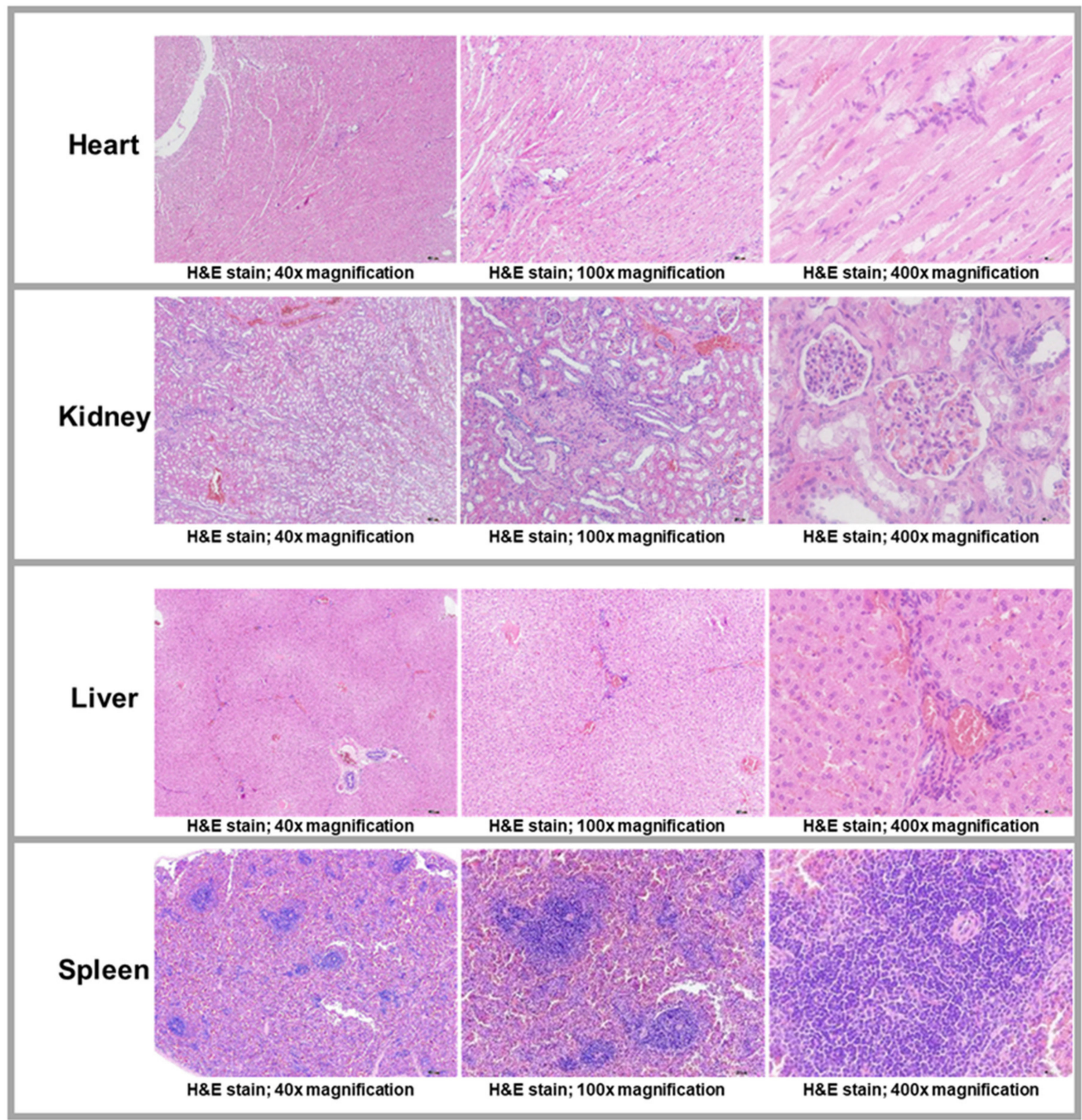

Figure 8. Histopathological examinations of visceral organs (heart, kidney, liver, and spleen). The specimens were obtained from one of the animals implanted with an iron bioabsorbable triple-helix suture anchor. Scale from $40 \times, 100 \times$, and $400 \times$, respectively. H\&E stain: hematoxylin and eosin stain. 


\section{Liver}
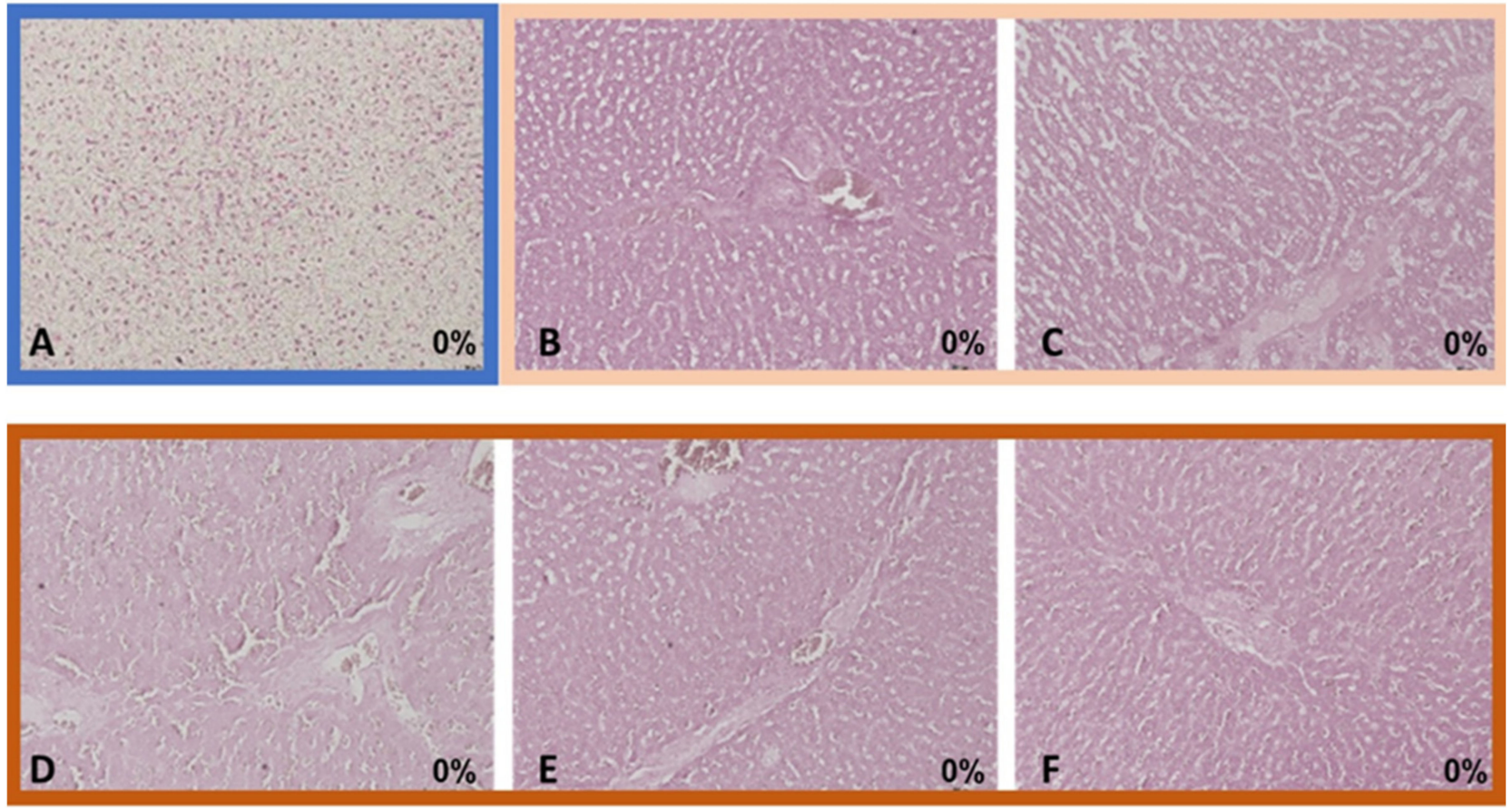

Spleen
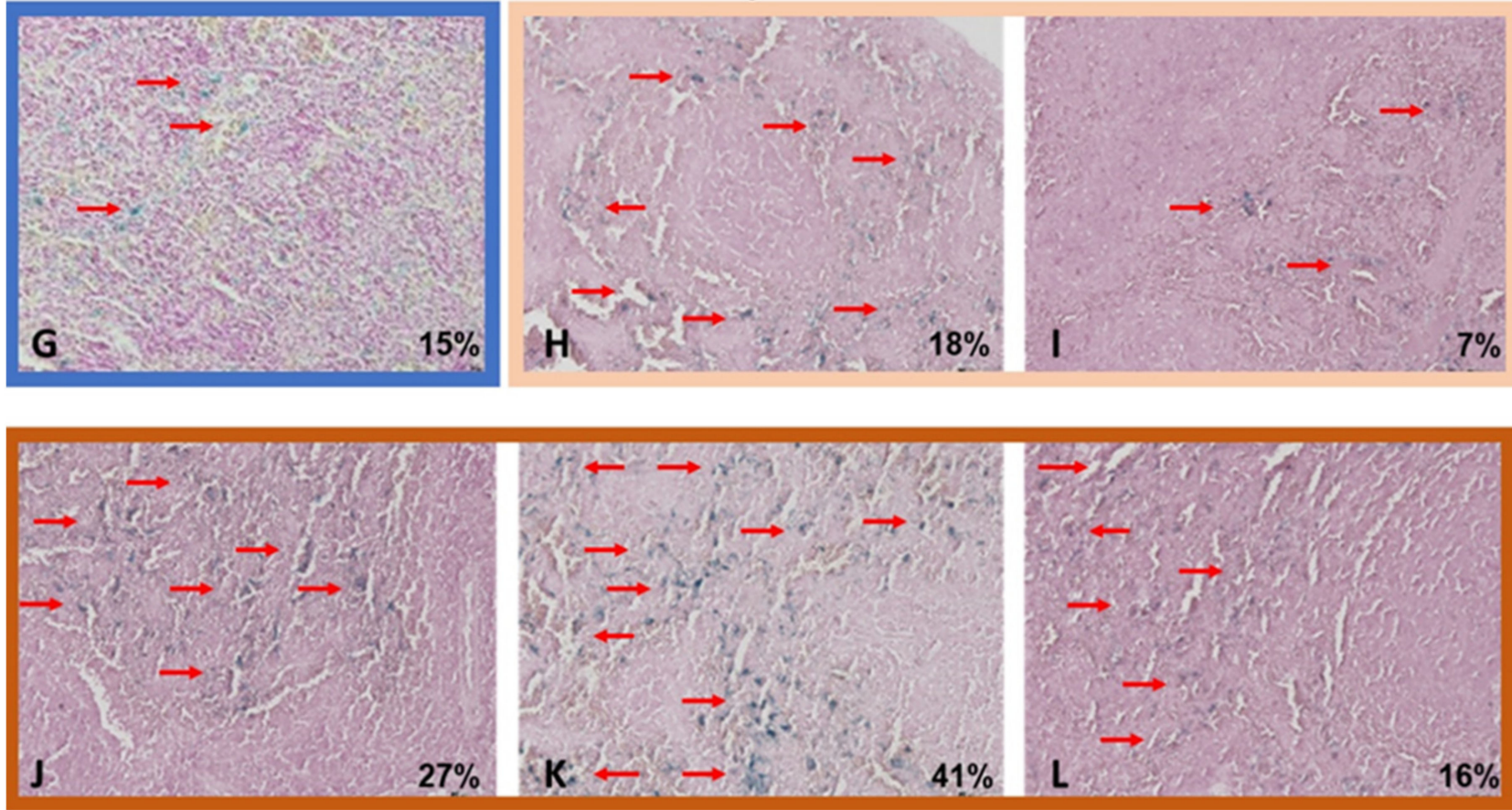

Figure 9. Prussian blue staining of the liver $(\mathbf{A}-\mathbf{F})$ and spleen $(\mathbf{G}-\mathbf{L})$. The specimens were obtained from the polymer SA group $(\mathbf{A}, \mathbf{G})$, iron SA_2 helix group $(\mathbf{B}, \mathbf{C}, \mathbf{H}, \mathbf{I})$, and iron SA_3 helix group (D-F,J-L), respectively. Red arrows indicate identified iron stain clusters. Magnification: $200 \times$. 
Table 7. Semi-quantitative results for the Prussian blue staining of the liver and spleen.

\begin{tabular}{ccccc}
\hline & \multicolumn{3}{c}{ Semi-Quantitative Analysis for Prussian-Blue (Iron Stain) of Spleen } \\
& $\begin{array}{c}\text { Simple Scoring of } \\
\text { Spleen Iron Store }\end{array}$ & $\begin{array}{c}\text { Percentage of Spleen } \\
\text { Iron Store (\%) }\end{array}$ & $\begin{array}{c}p \text { Value vs. } \\
\text { Polymer SA }\end{array}$ & $\begin{array}{c}p \text { Value vs. } \\
\text { Iron SA_2 Helix }\end{array}$ \\
\hline Polymer SA & + & $25.5 \pm 14.8$ \\
Iron SA_2 Helix & + & $22.4 \pm 11.8$ & 0.6967 \\
Iron SA_3 Helix & + & $24.9 \pm 16.1$ & 0.9477 \\
& Semi-Quantitative Analysis for Prussian-Blue (Iron Stain) of Liver \\
Polymer SA & \multicolumn{4}{c}{ Simple Scoring for Iron Store in Liver } \\
Iron SA_2 Helix & \multicolumn{3}{c}{ Not Detectable (ND) } \\
Iron SA_3 Helix & \multicolumn{3}{c}{ Not Detectable (ND) } \\
\hline
\end{tabular}

\section{Discussion}

Our iron SAs had double- or triple-helical threads, a porous structure, and an open architecture design to maximize the contact surface, increase initial stability, and facilitate bone growth (Figure 1A). The findings of the in vitro mechanical analysis revealed that the ultimate pullout strength of the iron SA group was higher than that of the polymer SA group (Figure 1B and Table 1). Poly(lactic-co-glycolic acid) is the main material (accounting for $65 \%$ ) of a polymer SA $[28,29]$. However, our iron SA was prepared using metals; thus, the mechanical strength of the iron SA was higher than that of the polymer SA. Higher mechanical strength contributed to the higher pullout strength of the iron SA groups. In addition, the triple-helical design showed more favorable mechanical performance compared with the double-helical design. These findings suggest that not only a higher mechanical strength but also a larger contact surface area resulted in more satisfactory ultimate pullout performance. On the other hand, these results also demonstrated the significantly better implant-bone integration in the iron-based SA groups at 12 weeks after implantation compared to those at 4 weeks after implantation.

Biocompatibility is a major concern for an iron-based bioabsorbable material. A biocompatible material should exert minimal inflammatory and toxic effects both locally and systemically after its degradation [5,30-32]. In addition, the biocompatibility of a product's surface is crucial [30]. Our iron-based SAs demonstrated satisfactory biocompatibility from several aspects. First, the results of the MTT assay and SEM analysis demonstrated no significant cytotoxicity of the extract or implant surface (Figure 2 and Table 2). Second, the in vivo biochemical analysis (Figure 6 and Table 6) and histopathological (Figure 8) analysis of the visceral organs revealed no significant increase in iron, ALT, Cr, and BUN concentrations and tissue toxicity. Moreover, semi-quantitative results for iron ion staining in the liver and spleen did not significantly differ between the iron SA and polymer SA groups (Figure 9 and Table 7). These findings are compatible with those of previous studies reporting the biocompatibility of iron-based implants $[4,5,31,33,34]$. In summary, iron SAs were biocompatible after short-term implantation in a rabbit animal model.

The synthetic polymer SA used in this study consisted of $20 \%$ calcium sulfate and $15 \%$ $\beta$-TCP [27-29] and was expected to result in favorable bone growth. Our histological and micro-CT examination demonstrated favorable bone growth; these findings are compatible with those of previous studies [27-29]. As shown in Figure 2B, the results of SEM analysis demonstrated cell attachment on the implant with lamellipodial and filopodial extrusions; this result is compatible with the histopathological finding (Figure 7) that demonstrated satisfactory cell contact with the implant. In addition, the micro-CT results revealed similar $\mathrm{BV} / \mathrm{TV}$ and BS/TV between the polymer SA and iron SA groups (Figure 4 and Table 4), suggesting that all implants showed similar bone growth. These findings suggest that both the polymer and iron SAs resulted in similar total bone growth and demonstrated bone formation closer to the implant surface.

Similar to a polymer SA that shows favorable contact interface biocompatibility, iron SAs demonstrated bone-implant contact interface biocompatibility, as observed in SEM and 
histological analyses (Figures 2 and 7). This finding is compatible with those of previous studies $[5,13,30]$.

According to previous literatures, metallic SA had superior pullout strength compared to polymer SA [35-37]. In addition, increased threads surface area of SA (Figure 1B) also contributed to better pullout strength $[38,39]$. In combination of material superiority, triplehelical geometry design to increase thread-bone contact surface area, and integrated porous design of iron SAs could maximize the bone-implant contact interface and increase its biocompatibility and result in better in vivo biomechanical pullout strength of the iron SA than that of the polymer SA (Figure 3 and Table 3 ).

To more effectively delineate and quantify the implant degradation profile, we performed micro-CT analysis. As shown in Figure 5 and Table 5, the implant structure thickness and SSV percentage at 4 and 12 weeks postoperatively significantly decreased after implantation compared with before implantation. However, the implant structure thickness and SSV did not significantly differ between 4 and 12 weeks after surgery. These findings indicate that the iron implant rapidly degraded during the first 4 weeks after implantation and then slowly degraded after 4 weeks. This finding is compatible with those of previous studies indicating that the initial oxidation of iron formed a protective layer, thus preventing further degradation $[5,13,30,33,34]$.

Our study has some limitations that should be addressed. First, the study was only conducted for 12 weeks. Although our short-term in vivo biochemical and histopathological analyses showed high biocompatibility of iron SAs, future clinical studies should examine their long-term biocompatibility. Second, local and systemic degradation profiles of iron should be explored and established. In this study, we examined the degradation profile of iron only by performing histopathological analysis and micro-CT. Future studies should focus on wider aspects of the iron degradation profile, particularly under different physiological conditions. Third, we used a small animal in this study; however, the implant volume and weight were designed for human use. To obtain more accurate and realistic data, future studies should use animals with physiological parameters similar to those of humans.

\section{Materials and Methods}

\subsection{Production and In Vitro Tests of Iron SAs Developed Using AM Technology}

The innovative porous iron SA was produced using AM selective laser sintering technology (SLM EOSINT M 270 model; EOS GambH-Electro Optical Systems, Krailling, Germany). The suture anchors were designed to have a circular cross section with doubleand triple-helical threads and an integrated porous structure to increase their surface area and provide high initial stability after implantation (Figure 1A). The suture anchors were prepared using the bioabsorbable spherical iron powder with an Fe purity of $>99.5 \%$ [40].

In vitro mechanical tests were conducted to evaluate the mechanical characteristics of the suture anchors. The tests were performed using a 15-pound per cubic foot (pcf) polyurethane foam block (part\#1522-02; Sawbone, Pacific Research Laboratories, Vashon, WA, USA). For comparison, commercialized bioabsorbable polymer SAs (5.5-mm Healicoil PK Suture Anchor, Smith \& Nephew, London, UK) were used as the control. A No. 2 high-tensile-strength suture (FiberWire, Arthrex, Naples, FL, USA) with equal limbs was threaded through the suture eyelet, looped, and fixed over a post on the adapter before mechanical testing. The static ultimate pullout strength was examined at a displacement rate of $12.5 \mathrm{~mm} / \mathrm{s}$. The mechanical tests were performed using Instron E3000 (ElectroPuls, Instron, MA, USA).

The 3-(4,5-dimethylthiazol-2-yl)-2,5-diphenyl tetrazolium bromide (MTT) assay (M6494, Invitrogen, Thermo Fisher Scientific, Waltham, MA, USA) and scanning electron microscope (SEM) (DSM940 Zeiss model, Carl-Zeiss AG, Oberkochen, Germany) analyses were performed in vitro to evaluate the cytotoxicity of the suture anchor. For the MTT assay, mouse fibroblast cells (CRCC 60091 NCTN Clone 929) were used. The cells were seeded into 96-well plates $(1 \times 104$ cells/well $)$ and cultured in $\alpha$-MEM supplemented with $10 \%$ 
fetal bovine serum at $37^{\circ} \mathrm{C}$ in $5 \% \mathrm{CO}_{2}$ for $24 \mathrm{~h}$. Subsequently, the cells were treated with $100 \mu \mathrm{L}$ the iron SAs extract (the extraction ratio of the iron SAs was $0.2 \mathrm{~g}$ in $1 \mathrm{~mL} \alpha-\mathrm{MEM}$ supplemented with $10 \%$ fetal bovine serum) and incubated at $37{ }^{\circ} \mathrm{C}$ in $5 \% \mathrm{CO}_{2}$ for $24 \mathrm{~h}$ [40]. After the iron SAs extract treatment, the cells were incubated with MTT $(50 \mu \mathrm{L} /$ well) at $37^{\circ} \mathrm{C}$ ) in $5 \% \mathrm{CO}_{2}$ for $4 \mathrm{~h}$, and then $200 \mu \mathrm{L}$ of DMSO was added. The absorbance of individual wells was determined at $570 \mathrm{~nm}$. For the SEM examination, MG-63 cells (ATCC ${ }^{\circledR}$ CRL-1427TM), a human bone osteosarcoma cell line, were incubated in $\alpha$ MEM supplemented with $10 \%$ fetal bovine serum and iron SAs $(2 \times 105 / 50 \mu \mathrm{L}$ for each implant $)$ at $37^{\circ} \mathrm{C}$ in $5 \% \mathrm{CO}_{2}$ for 14 days before performing SEM examination.

\subsection{In Vivo Animal Study Design}

All animal experiments were approved by the Ethics Committee of the Biomedical Technology and Device Research Laboratories of Industrial Technology Research Institute in accordance with national animal welfare legislation (approval no.: MI-20190602), and the study protocol conformed to the National Institute of Health guidelines for the use of laboratory animals. A total of 54 New Zealand white rabbits (Master Laboratory Co., Taiwan) with a mean body weight of $3.5 \pm 0.5 \mathrm{~kg}$ at the age of 6 months were selected. The rabbits were randomized into experimental and control groups by using the computergenerated randomization method. In the control group, a polymer SA was implanted in one of the distal femoral condyles of the stifle joints. By contrast, in the experimental group, a bioabsorbable iron SA with double- or triple-helical threads was implanted using the same surgical procedure as in the control group (Iron SA_2 helix and Iron SA_3 helix groups, respectively). All the three groups were further divided into two subcategories based on the implantation periods of 4 and 12 weeks after surgery (18 in each group). Histological analysis was performed in six rabbits in each group, whereas micro-CT and biomechanical tests were performed in the remaining 12 rabbits. Micro-CT was performed in each animal immediately at the end of each experiment. Subsequently, the specimens were freshly frozen for use in further biomechanical tests.

\subsection{Surgical Methods}

All surgical procedures were performed under general anesthesia by administering an intramuscular injection of a Zoletil-Rompun mixture (Zoletil $15 \mathrm{mg} / \mathrm{kg}$; Rompun 0.05 mL/kg; Zoletil, Virbac Taiwan, Taipei, Taiwan; Rompun, Bayer Taiwan, Taipei, Taiwan). To induce analgesia, the rabbits were given meloxicam $(0.15 \mathrm{mg} / \mathrm{kg}$ peroral; Metacam, Boehringer Ingelheim Taiwan, Taiwan) 1 day preoperatively, immediately preoperatively, and 2 days following surgery.

Surgical procedures were performed following the method reported by Yamakado et al. with some modification [41]. Briefly, lateral parapatellar arthrotomy was performed in one of the stifle joints to gain access to the outer cortex of the lateral femoral condyle. A tapered hole (4.5-mm in maximal diameter) was made using a bone awl perpendicular to the long axis of the femur. Subsequently, the suture anchor was screwed in through the axis of the hole. After correct placement of the suture anchor, the joint capsule, muscles, subcutis, and cutis were separately closed using an absorbable suture material (Vicryl 4-0; Ethicon, NJ, USA). After surgery, the animals were returned to their cages and were free to move without any restriction or immobilization of their extremities. All animals were found to be ambulant without signs of guarding or immobility when they were sacrificed. For biochemical analysis, the concentrations of iron, alanine transaminase (ALT), creatinine $(\mathrm{Cr})$, and blood urea nitrogen (BUN) were determined preoperatively and at 4,8 , and 12 weeks postoperatively. At the end of experiments, all animals were euthanized by administering an intravenous overdose of pentobarbital. Their liver, kidneys, heart, spleen, and stifle joints were retrieved and stored at $-20{ }^{\circ} \mathrm{C}$ until future analysis. 


\subsection{Biomechanical Analysis}

Six rabbits were sacrificed at 4 and 12 weeks postoperatively, respectively, and their stifle joints were retrieved and used in biomechanical analysis. The distal femur was harvested along with the implants. A material testing machine (Instron E3000; ElectroPuls, Instron, MA, USA) was used for biomechanical testing. The test was performed at room temperature $\left(25^{\circ} \mathrm{C}\right)$ in a moist environment. After the removal of the redundant tissue, the femur was fixed at the base plate with the long axis of the implant being parallel to the tensile force direction, and a No. 2 high-tensile-strength suture (FiberWire, Arthrex, Naples, FL, USA) with equal limbs was threaded through the suture eyelet, looped, and fixed over a post on the load cell. The tensile load parallel to the long axis of the suture anchors was examined at a strain rate of $0.5 \mathrm{~mm} / \mathrm{min}$ until the occurrence of failure. The ultimate pullout load and the failure mode of the constructs were recorded and analyzed.

\subsection{Micro-CT Analysis}

After sacrificing the rabbits, six specimens were retrieved from each group and scanned using a multi-scale nano-CT (Skyscan 2211, Bruker Micro-CT, Kontich, Belgium) at a voxel resolution of $18 \mu \mathrm{m}$. A $360^{\circ}$ scan with a high voltage of $160 \mathrm{kVp}$, a current of $140 \mu \mathrm{A}$, and an output of $20 \mathrm{~W}$ was conducted. Image reconstruction was performed using the reconstruction software InstaRecon xCBR (version 2.0.4.6, InstaRecon, Champaign, IL, USA) and NRecon (Bruker Micro-CT, Kontich, Belgium). Ring artifact and beam-hardening correction were performed using NRecon (Bruker Micro-CT, Kontich, Belgium).

Reconstructed cross sections were reorientated, and the region of interest (ROI) was selected. We performed the analysis using $5-\mathrm{mm}$ ( 278 slices) images. Thresholding and bone growth analysis were performed using CTAn software. The ROI of the implant $(6.25 \mathrm{~mm}$ in diameter) was segmented before performing bone growth analysis. A $0-1000-\mu \mathrm{m}$ region around the implant was defined as the ROI for the bone growth analysis (Figure 4A). The metallic structure and bone were separately isolated based on the difference in X-ray absorption. The border of the metallic structure was examined using CTAn software with the shrink-wrap algorithm. Tissue volume $\left(\mathrm{TV}, \mathrm{mm}^{3}\right)$, bone volume $\left(\mathrm{BV}, \mathrm{mm}^{3}\right)$, percent bone volume (BV/TV, \%), bone surface area $\left(\mathrm{BS}, \mathrm{mm}^{2}\right)$, and bone surface area per total volume (BS/TV, 1/mm) were measured 0-1000 $\mu \mathrm{m}$ above the metallic implant bone. Subsequently, a "sphere-fitting" measurement method was used to analyze the thickness of the structure and the implant structure (ST; mm) [42-44]. In addition to the bone formation analysis, implant degradation profile analysis was performed. Small implant fragments with a diameter of $<0.18 \mathrm{~mm}$ that were detected in the ROI were defined as the small-structure volume (SSV), and the implant volume in the ROI was defined as the object volume (OV). SSV /OV (\%) denoted the percentage of small fragments to that of the implant in the ROI. Three-dimensional visualization was performed using Avizo software (Thermo Fisher Scientific, Waltham, MA, USA) and CTVox (Bruker Micro-CT, Kontich, Belgium).

\subsection{Histological Analysis}

Four specimens were retrieved from each group for histological analysis 3 months postoperatively. All the harvested samples were fixed in 10\% formalin for 14 days and sequentially dehydrated with increasing concentrations of ethanol $(70 \%, 95 \%$, and $100 \%)$ for at least 1 day and infiltrated for 5 days by using polymethylmethacrylate. After embedding, the samples were cut vertically, perpendicular to the long axis of the suture anchor, at the level of the respective bone-implant interfaces. The sections were cut to approximately $150 \mu \mathrm{m}$ in thickness by using a low-speed saw (IsoMet, Buehler, Lake Bluff, IL, USA) and ground to $60 \mu \mathrm{m}$ by using a grinding and polishing machine. The ground sections were stained with Sanderson's rapid bone stain (Dorn \& Hart Microedge Inc., Loxley, AL, USA) and then counterstained with acid fuchsin. All bone-implant interfaces were carefully examined under a light microscope (Nikon Eclipse Ti-series, Melville, NY, USA). 
Nine sets of visceral organs, namely the liver, kidney, heart, and spleen, from each group were stained with hematoxylin and eosin $(\mathrm{H} \& \mathrm{E})$, and the remaining sets were stained with Prussian blue and semi-quantified under a light microscope.

\subsection{Statistical Analysis}

All experimental data are presented as the mean \pm standard deviation, with values obtained from more than three experiments. The Wilcoxon rank-sum test and Fisher's exact test were used for nonparametric analysis. Data of more than two groups were compared using one-way analysis of variance and Tukey's post hoc test for repeated measures. The correlation was examined by determining Pearson and Spearman correlation coefficients. A $p$ value of $<0.05$ was considered statistically significant. Statistical analysis was performed using PASW software (SPSS, Chicago, IL, USA).

\section{Conclusions}

In conclusion, the results of the present study exhibited that the iron SAs with triplehelical threads had the significantly better ultimate pull-out strength compared to the iron SAs with double-helical counterparts and synthetic polymer SAs, especially at the early stage after implantation. On the other hand, the open architecture design and integrated porous structure of bioabsorbable iron SAs demonstrated better biocompatibility both locally and systemically after short-term implantation. The histopathological examination of visceral organs (heart, kidney, liver, and spleen) in the iron SA groups showed no significant differences compared to those in the synthetic polymer SA group. In summary, the bioabsorbable iron SAs combined the advantages of the mechanical superiority of the iron metal and the possibility of absorption after implantation, making them a suitable candidate for further development.

Author Contributions: K.-Y.Y., C.-C.H., S.-IH., W.-C.L., J.-S.S., P.-IT. and C.-Y.C. conducted conceptualization; C.-C.T., H.-L.L., C.-K.L. (Chen-Kun Liaw), Y.-M.H., C.-C.H., S.-IH. and W.-C.L. performed data curation; C.-C.T., H.-L.L., C.-C.H., C.-K.L. (Chen-Kun Liaw), Y.-M.H., S.-IH. and W.-C.L. conducted the formal analysis; P.-IT. and C.-Y.C. assisted in funding acquisition; C.-C.T., H.-L.L., K.-Y.Y. and C.-C.H. conducted investigation; S.-IH., C.-K.L. (Chun-Kuan Lu) and C.-Y.C. designed the methodology; H.-H.S., J.-S.S., P.-IT. and C.-Y.C. contributed to project administration; K.-Y.Y., C.-C.H. and P.-IT. obtained the resources; K.-Y.Y., C.-C.H. and T.-H.L. operated software; Y.-H.H., H.-H.S., P.-IT. and C.-Y.C. supervised the study; C.-K.L. (Chen-Kun Liaw), Y.-M.H., Y.-H.H., K.-Y.Y., C.-C.H. and T.-H.L. validated the method; C.-C.T., H.-L.L., C.-K.L. (Chen-Kun Liaw), Y.-M.H., K.-Y.Y., C.-C.H. and T.-H.L. contributed to visualization; C.-C.T., H.-L.L., K.-Y.Y. and C.-C.H. prepared the original draft; C.-C.H., H.-H.S., J.-S.S., P.-IT. and C.-Y.C. reviewed and edited the manuscript. All authors have read and agreed to the published version of the manuscript.

Funding: This study was supported by grants from Taipei Medical University-Shuang Ho Hospital 201956F0020 (Chih-Yu Chen), Kaohsiung Medical University Hospital (KMUH107-7R51), and Industrial Technology Research Institute: J356EX3200 (Pei-I. Tsai).

Institutional Review Board Statement: Our animal study protocol was reviewed and approved by the Institutional Animal Care and Use Committee (IACUC) of Master Laboratory (approval no.: MI-20190602).

Data Availability Statement: The datasets generated and/or analyzed during the current study are not publicly available because they contain trade secrets but can be made available from the corresponding author on reasonable request.

Acknowledgments: We would like to thank Hong-Jen Lai (Material and Chemical Research Laboratories, Industrial Technology Research Institute, Chutung, Hsinchu County, Taiwan) for providing technical support in this study.

Conflicts of Interest: The authors declare no conflict of interest. 


\section{References}

1. Park, J.B.; Bronzino, J.D. Biomaterials: Principles and Applications, 1st ed.; CRC Press: Boca Raton, FL, USA, 2002.

2. Joung, Y.-H. Development of implantable medical devices: From an engineering perspective. Int. Neurourol. J. 2013, 17, 98. [CrossRef] [PubMed]

3. Khan, W.; Muntimadugu, E.; Jaffe, M.; Domb, A.J. Implantable medical devices. In Focal Controlled Drug Delivery; Springer: Berlin/Heidelberg, Germany, 2014; pp. 33-59. [CrossRef]

4. Han, H.-S.; Loffredo, S.; Jun, I.; Edwards, J.; Kim, Y.-C.; Seok, H.-K.; Witte, F.; Mantovani, D.; Glyn-Jones, S. Current status and outlook on the clinical translation of biodegradable metals. Mater. Today 2019, 23, 57-71. [CrossRef]

5. Shuai, C.; Li, S.; Peng, S.; Feng, P.; Lai, Y.; Gao, C. Biodegradable metallic bone implants. Mater. Chem. Front. 2019,3 , 544-562. [CrossRef]

6. Ramakrishna, S.; Mayer, J.; Wintermantel, E.; Leong, K.W. Biomedical applications of polymer-composite materials: A review. Compos. Sci. Technol. 2001, 61, 1189-1224. [CrossRef]

7. Li, C.; Guo, C.; Fitzpatrick, V.; Ibrahim, A.; Zwierstra, M.J.; Hanna, P.; Lechtig, A.; Nazarian, A.; Lin, S.J.; Kaplan, D.L. Design of biodegradable, implantable devices towards clinical translation. Nat. Rev. Mater. 2020, 5, 61-81. [CrossRef]

8. Ramsay, S.D.; Pilliar, R.M.; Santerre, J.P. Fabrication of a biodegradable calcium polyphosphate/polyvinyl-urethane carbonate composite for high load bearing osteosynthesis applications. J. Biomed. Mater. Res. Part B Appl. Biomater. 2010, 94, 178-186. [CrossRef]

9. Figueiredo, L.; Fonseca, R.; Pinto, L.F.; Ferreira, F.C.; Almeida, A.; Rodrigues, A. Strategy to improve the mechanical properties of bioabsorbable materials based on chitosan for orthopedic fixation applications. J. Mech. Behav. Biomed. Mater. 2020, 103, 103572. [CrossRef]

10. Staiger, M.P.; Pietak, A.M.; Huadmai, J.; Dias, G. Magnesium and its alloys as orthopedic biomaterials: A review. Biomaterials 2006, 27, 1728-1734. [CrossRef] [PubMed]

11. Witte, F. The history of biodegradable magnesium implants: A review. Acta Biomater. 2010, 6, 1680-1692. [CrossRef]

12. Yusop, A.H.M.; Daud, N.M.; Nur, H.; Kadir, M.R.A.; Hermawan, H. Controlling the degradation kinetics of porous iron by poly (lactic-co-glycolic acid) infiltration for use as temporary medical implants. Sci. Rep. 2015, 5, 1-17. [CrossRef] [PubMed]

13. Gorejová, R.; Oriňaková, R.; Orságová Králová, Z.; Baláž, M.; Kupková, M.; Hrubovčáková, M.; Haverová, L.; Džupon, M.; Oriňak, A.; Kal'avský, F. In vitro corrosion behavior of biodegradable iron foams with polymeric coating. Materials 2020, 13, 184. [CrossRef]

14. Kraus, T.; Moszner, F.; Fischerauer, S.; Fiedler, M.; Martinelli, E.; Eichler, J.; Witte, F.; Willbold, E.; Schinhammer, M.; Meischel, M. Biodegradable Fe-based alloys for use in osteosynthesis: Outcome of an in vivo study after 52 weeks. Acta Biomater. 2014, 10, 3346-3353. [CrossRef] [PubMed]

15. Francis, A.; Yang, Y.; Virtanen, S.; Boccaccini, A. Iron and iron-based alloys for temporary cardiovascular applications. J. Mater. Sci. Mater. Med. 2015, 26, 1-16. [CrossRef] [PubMed]

16. Zivic, F.; Grujovic, N.; Pellicer, E.; Sort, J.; Mitrovic, S.; Adamovic, D.; Vulovic, M. Biodegradable metals as biomaterials for clinical Practice: Iron-based materials. In Biomaterials in Clinical Practice, 1st ed.; Springer International Publishing: Berlin/Heidelberg, Germany, 2018; pp. 225-280.

17. Hong, D.; Chou, D.-T.; Velikokhatnyi, O.I.; Roy, A.; Lee, B.; Swink, I.; Issaev, I.; Kuhn, H.A.; Kumta, P.N. Binder-jetting 3D printing and alloy development of new biodegradable Fe-Mn-Ca/Mg alloys. Acta Biomater. 2016, 45, 375-386. [CrossRef]

18. Schinhammer, M.; Steiger, P.; Moszner, F.; Löffler, J.F.; Uggowitzer, P.J. Degradation performance of biodegradable FeMnC (Pd) alloys. Mater. Sci. Eng. C 2013, 33, 1882-1893. [CrossRef] [PubMed]

19. Cheng, J.; Huang, T.; Zheng, Y. Microstructure, mechanical property, biodegradation behavior, and biocompatibility of biodegradable Fe-Fe2O3 composites. J. Biomed. Mater. Res. Part A 2014, 102, 2277-2287. [CrossRef]

20. Tsai, P.I.; Chen, C.Y.; Huang, S.W.; Yang, K.Y.; Lin, T.H.; Chen, S.Y.; Sun, J.S. Improvement of bone-tendon fixation by porous titanium interference screw: A rabbit animal model. J. Orthop. Res. 2018, 36, 2633-2640. [CrossRef]

21. Putra, N.; Leeflang, M.; Minneboo, M.; Taheri, P.; Fratila-Apachitei, L.; Mol, J.; Zhou, J.; Zadpoor, A. Extrusion-based 3D printed biodegradable porous iron. Acta Biomater. 2021, 121, 741-756. [CrossRef]

22. Zadpoor, A.A. Bone tissue regeneration: The role of scaffold geometry. Biomater. Sci. 2015, 3, 231-245. [CrossRef]

23. Wegener, B.; Sichler, A.; Milz, S.; Sprecher, C.; Pieper, K.; Hermanns, W.; Jansson, V.; Nies, B.; Kieback, B.; Müller, P.E. Development of a novel biodegradable porous iron-based implant for bone replacement. Sci. Rep. 2020, 10, 1-10. [CrossRef]

24. Chahla, J.; Liu, J.N.; Manderle, B.; Beletsky, A.; Cabarcas, B.; Gowd, A.K.; Inoue, N.; Chubinskaya, S.; Trenhaile, S.; Forsythe, B. Bony ingrowth of coil-type open-architecture anchors compared with screw-type PEEK anchors for the medial row in rotator cuff repair: A randomized controlled trial. Arthrosc. J. Arthrosc. Relat. Surg. 2020, 36, 952-961. [CrossRef] [PubMed]

25. Kim, J.-H.; Kim, Y.-S.; Park, I.; Lee, H.-J.; Han, S.-Y.; Jung, S.; Shin, S.-J. A comparison of open-construct PEEK suture anchor and non-vented biocomposite suture anchor in arthroscopic rotator cuff repair: A prospective randomized clinical trial. Arthrosc. J. Arthrosc. Relat. Surg. 2020, 36, 389-396. [CrossRef] [PubMed]

26. Milewski, M.D.; Diduch, D.R.; Hart, J.M.; Tompkins, M.; Ma, S.-Y.; Gaskin, C.M. Bone replacement of fast-absorbing biocomposite anchors in arthroscopic shoulder labral repairs. Am. J. Sports Med. 2012, 40, 1392-1401. [CrossRef]

27. Prabhu, B.; Karau, A.; Wood, A.; Dadsetan, M.; Liedtke, H.; DeWitt, T. Bioresorbable Materials for Orthopedic Applications (Lactide and Glycolide Based). In Orthopedic Biomaterials; Springer: Berlin/Heidelberg, Germany, 2018; pp. $287-344$. 
28. Park, K.; Skidmore, S.; Hadar, J.; Garner, J.; Park, H.; Otte, A.; Soh, B.K.; Yoon, G.; Yu, D.; Yun, Y. Injectable, long-acting PLGA formulations: Analyzing PLGA and understanding microparticle formation. J. Control. Release 2019, 304, 125-134. [CrossRef] [PubMed]

29. Yamauchi, S.; Tsukada, H.; Sasaki, E.; Sasaki, S.; Kimura, Y.; Yamamoto, Y.; Tsuda, E.; Ishibashi, Y. Biomechanical analysis of bioabsorbable suture anchors for rotator cuff repair using osteoporotic and normal bone models. J. Orthop. Sci. 2021. [CrossRef]

30. Gorejová, R.; Haverová, L.; Oriňaková, R.; Oriňak, A.; Oriňak, M. Recent advancements in Fe-based biodegradable materials for bone repair. J. Mater. Sci. 2019, 54, 1913-1947. [CrossRef]

31. Traverson, M.; Heiden, M.; Stanciu, L.A.; Nauman, E.A.; Jones-Hall, Y.; Breur, G.J. In vivo evaluation of biodegradability and biocompatibility of Fe30Mn alloy. Vet. Comp. Orthop. Traumatol. 2018, 31, 10-16.

32. Hermawan, H. Updates on the research and development of absorbable metals for biomedical applications. Prog. Biomater. 2018, 7, 93-110. [CrossRef]

33. Peuster, M.; Hesse, C.; Schloo, T.; Fink, C.; Beerbaum, P.; von Schnakenburg, C. Long-term biocompatibility of a corrodible peripheral iron stent in the porcine descending aorta. Biomaterials 2006, 27, 4955-4962. [CrossRef]

34. Yang, Y.; Zhou, J.; Detsch, R.; Taccardi, N.; Heise, S.; Virtanen, S.; Boccaccini, A.R. Biodegradable nanostructures: Degradation process and biocompatibility of iron oxide nanostructured arrays. Mater. Sci. Eng. C 2018, 85, 203-213. [CrossRef]

35. Visscher, L.E.; Jeffery, C.; Gilmour, T.; Anderson, L.; Couzens, G. The history of suture anchors in orthopaedic surgery. Clin. Biomech. 2019, 61, 70-78. [CrossRef]

36. Barber, F.A.; Herbert, M.A. Cyclic loading biomechanical analysis of the pullout strengths of rotator cuff and glenoid anchors: 2013 update. Arthrosc. J. Arthrosc. Relat. Surg. 2013, 29, 832-844. [CrossRef]

37. Chaudhry, S.; Dehne, K.; Hussain, F. A review of suture anchors. Orthop. Trauma 2019, 33, 263-270. [CrossRef]

38. Chae, S.W.; Kang, J.Y.; Lee, J.; Han, S.H.; Kim, S.Y. Effect of structural design on the pullout strength of suture anchors for rotator cuff repair. J. Orthop. Res. ${ }^{\circledR}$ 2018, 36, 3318-3327. [CrossRef] [PubMed]

39. Horoz, L.; Hapa, O.; Barber, F.A.; Hüsemoğlu, B.; Özkan, M.; Havitçioğlu, H. Suture anchor fixation in osteoporotic bone: A biomechanical study in an ovine model. Arthrosc. J. Arthrosc. Relat. Surg. 2017, 33, 68-74. [CrossRef] [PubMed]

40. Huang, C.-C.; Lam, T.-N.; Amalia, L.; Chen, K.-H.; Yang, K.-Y.; Muslih, M.R.; Singh, S.S.; Tsai, P.-I.; Lee, Y.-T.; Jain, J. Tailoring grain sizes of the biodegradable iron-based alloys by pre-additive manufacturing microalloying. Sci. Rep. 2021, 11, 1-12.

41. Yamakado, K.; Kitaoka, K.; Yamada, H.; Hashiba, K.; Nakamura, R.; Tomita, K. The influence of mechanical stress on graft healing in a bone tunnel. Arthrosc. J. Arthrosc. Relat. Surg. 2002, 18, 82-90. [CrossRef]

42. Pyka, G.; Kerckhofs, G.; Schrooten, J.; Wevers, M. The effect of spatial micro-CT image resolution and surface complexity on the morphological 3D analysis of open porous structures. Mater. Charact. 2014, 87, 104-115. [CrossRef]

43. Chiu, Y.-R.; Hsu, Y.-T.; Wu, C.-Y.; Lin, T.-H.; Yang, Y.-Z.; Chen, H.-Y. Fabrication of asymmetrical and gradient hierarchy structures of poly-p-xylylenes on multiscale regimes based on a vapor-phase sublimation and deposition process. Chem. Mater. 2020, 32, 1120-1130. [CrossRef]

44. Van Dalen, G.; Koster, M. 2D \& 3D particle size analysis of micro-CT images. In Proceedings of the Bruker Micro-CT User Meeting, Brussels, Belgium, 13 November 2012; pp. 3-5. 